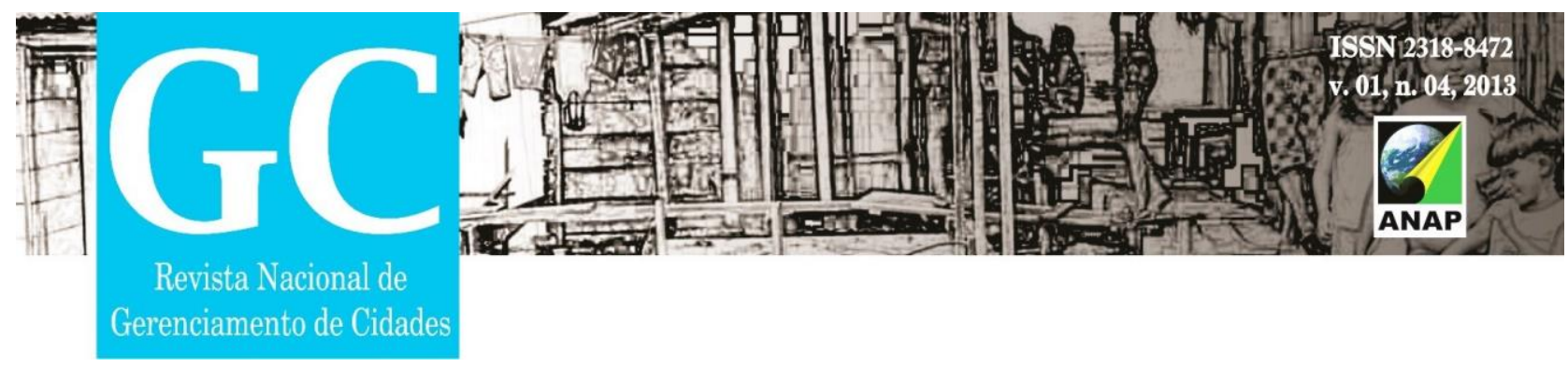

Titulo

\title{
O DESENVOLVIMENTO DE UMA CIDADE IGUALITÁRIA
}

Autora Principal

Meriéli Tamiles Oliveira Albergardi

Coautora

Luciana Harumi Okuyama

Orientadora

Jeane Aparecida Rombi de Godoy Rosin

Instituição

FACCAT - Faculdades de Ciências Contábeis e Administração de Empresas de Tupã

E-mail de contato

merieli.arq@hotmail.com

harumiokuyama@hotmail.com

Palavras-chave

Planejamento. Sustentabilidade. Cidade.

\section{INTRODUÇÃO}

Devido aos problemas constantemente enfrentados pelas cidades e na busca por soluções, surge o planejamento urbano, que na visão de Kohlsdorf (1985), é o fenômeno visto como algo dinâmico, ou seja, a cidade passa a ser vista como o produto de um determinado contexto histórico, e não mais como um modelo ideal a ser concebido pelos 


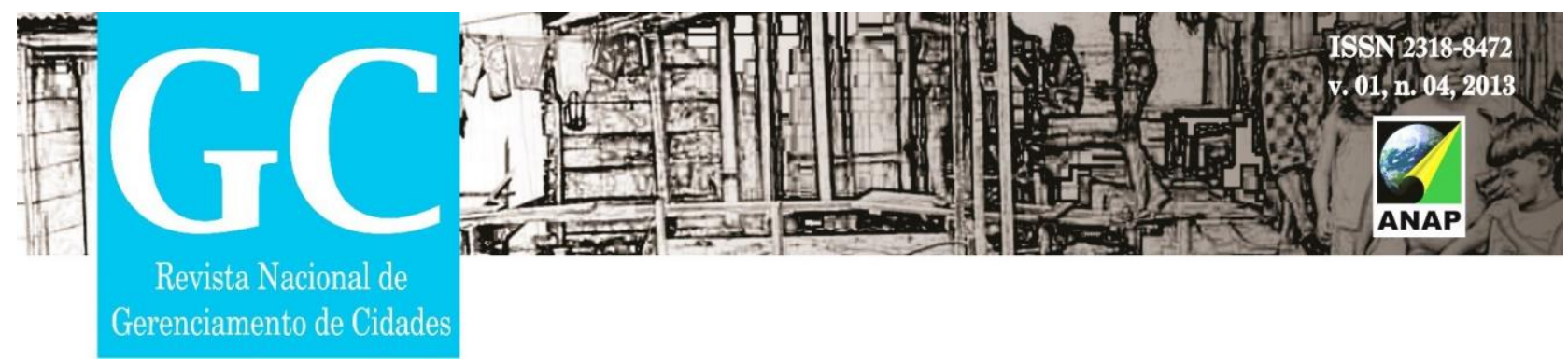

urbanistas. Solucionando assim, os problemas atuais que enfrentamos, analisando suas causas e propondo soluções eficazes.

No livro "Produzir Casas ou Construir Cidades" Ferreira (2012), o autor defende a ideia de que a desigualdade social é a maior causa das catástrofes urbanas, e atualmente essa diferença é visível nas cidades: de um lado bairros luxuosos e de outro favelas que abrigam os desfavorecidos. Os últimos por sua vez, não recebem investimentos por parte do governo, vivendo em condições precárias e, consequentemente, causando problemas ambientais.

Em 2008 o governo criou o Programa Minha Casa Minha Vida para aquecer o setor da construção civil, com objetivo de tornar acessível a moradia para a população de baixa renda. Mas por esse grupo social não ser exigente quanto à qualidade, o que está sendo construído pelo país é produção de qualidade muito duvidosa. E é por essa falta de alternativas de habitação que as pessoas vão para os assentamentos precários, áreas desvalorizadas, que no geral localiza-se fora da malha urbana.

Segundo Ferreira (2012), é necessário que a desigualdade acabe para assim minimizar os problemas urbanos que enfrentamos hoje, como por exemplo, as mudanças climáticas, que afeta diretamente nossas vidas. Caberia então, aos arquitetos e urbanistas projetar a cidade ideal, mas isso é impossível com uma sociedade idealizada, porque o que é "ideal" para uns não será para outros.

Desenvolveu-se no livro "Produzir Casas ou Construir Cidades" um estudo de como se obter um melhor planejamento para as nossas cidades, utilizando de projetos criados por escritórios brasileiros e um estrangeiro, e são estes que serão avaliados neste estudo. Com o intuito de descobrir como podemos construir cidades com a real qualidade arquitetônica e urbanística.

Inicia-se então, o processo de busca de soluções dos problemas existentes em unidades habitacionais, consistindo basicamente em identificar e analisar essas situações para a possível resolução dos mesmos.

Se houvesse uma distribuição de renda igualitária, todos usufruiriam dos mesmos direitos, tendo assim, melhores condições de vida. Mas é notório que somente os "privilegiados" se beneficiam, com melhores trabalhos, moradias e etc. 


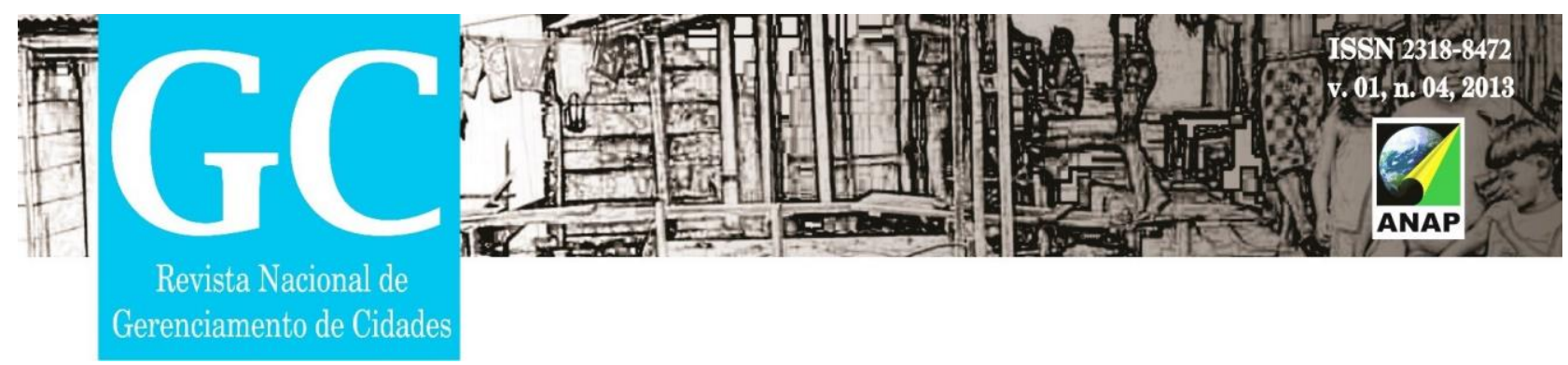

Com o grande aquecimento imobiliário, a falta de espaços para a implantação de edifícios, faz com que cresçam verticalmente e em áreas litorâneos preservadas trazendo dramáticos resultados urbanísticos. Como são áreas protegidas ambientalmente e há leis que proíbem construções nesses locais, deveria haver fiscalização por parte do governo, para que essas leis fossem cumpridas rigorosamente, mas que passam despercebidas, pois favorecem os cofres públicos e o bolso dos que ali se encontram.

É necessário investir na solução dos possíveis problemas, com investimentos em construções de parques, praças e locais para que as águas pluviais escoem com maior facilidade.

Segundo Ferreira (2012), a própria lei brasileira dificulta a construção de locais permeáveis. Há tantas exigências para que se edifique que as pessoas se esquecem da sustentabilidade ou que muitas vezes se torna economicamente inviável. Nessa questão, o Estado pensa apenas em seu benefício econômico, deixando de lado o bem estar da população, não faz jus ao nome de governo "público", que significa "que é do povo".

Para tais problemas que emerge o planejamento urbano. Seu objetivo não é simplesmente tentar reparar os danos já causados pela superpopulação. Ele vem para solucionar os problemas atuais que estamos enfrentando, analisando suas causas, propondo soluções eficazes para que não venha a ocorrer com as gerações futuras.

Portanto é necessário visar a sustentabilidade e garantir condições de vida digna no desenvolvimento de projetos residenciais. Avalia-se é quase impossível encontrarmos soluções arquitetônicas e urbanísticas perfeitas, mas quando vários problemas são resolvidos obtêm-se qualidade.

\section{OBJETIVO GERAL}

O objetivo desse estudo é analisar como podemos construir cidades com a real qualidade arquitetônica e urbanística diante dos problemas urbanos enfrentados, como por exemplo: enchentes, deslocamento de terras, mudanças climáticas, etc. Todos decorrentes da falta de planejamento. 


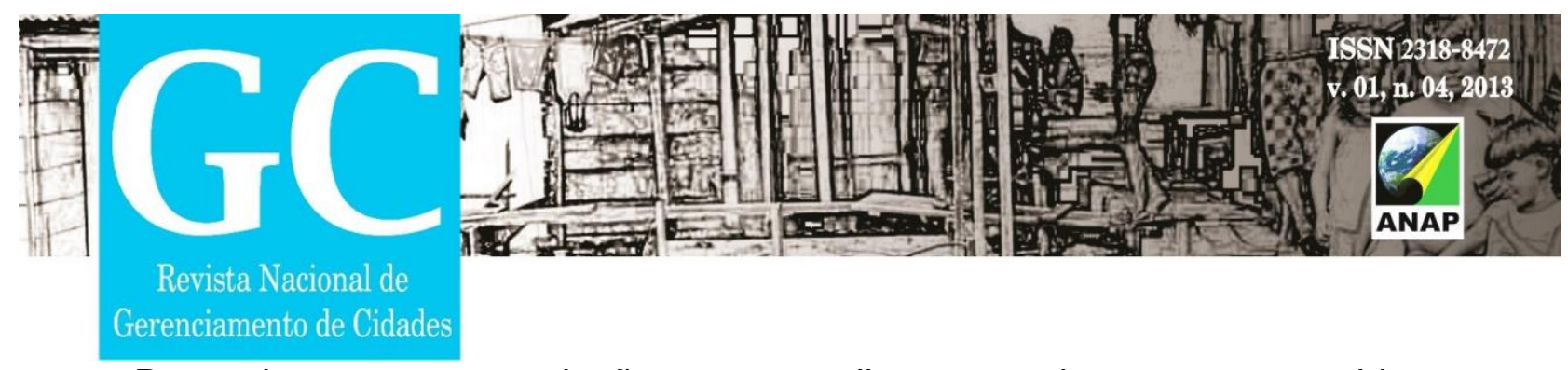

Pretende-se propor soluções que melhor se adaptem aos problemas que encontramos nas atuais cidades brasileiras, relacionados aos conjuntos habitacionais e seu planejamento inadequado.

\section{OBJETIVOS ESPECÍFICOS}

- Identificar a necessidade de se estabelecer soluções a serem aplicadas nas construções, selecionando as mais viáveis, social e economicamente;

- Analisar os projetos desenvolvidos dentro das leis de Uso e ocupação do Solo e do Plano Diretor, de acordo com as necessidades das classes sociais menos privilegiadas;

- Demonstrar a possibilidade de se construir conjuntos habitacionais dentro dos padrões do Programa Minha Casa Minha Vida, garantindo a inserção urbana, e oferecendo condições dignas de vida.

\section{METODOLOGIA}

Este estudo foi baseado no livro "Produzir casas ou construir cidades? Desafios para um novo Brasil urbano" Ferreira 2012, que aborda esse dilema apresentando propostas que elevam o padrão da produção atual. No livro, três escritórios brasileiros e um escritório estrangeiro de renome desenvolveram projetos no valor máximo por unidade de $R \$ 130.000,00$.

Para subsidiar o estudo, utilizou-se da técnica de pesquisa bibliográfica. Foram utilizados como base as normas da ABNT (Associação Brasileira de Norma Técnicas), o código de obras, o código sanitário, o plano diretor e as leis de Uso e Ocupação do Solo.

\section{RESULTADO (S)}

Destaca-se em todos os projetos descritos pelo livro, o cuidado com parâmetros essenciais à boa qualidade arquitetônica, estabelecendo outros padrões de vida em 


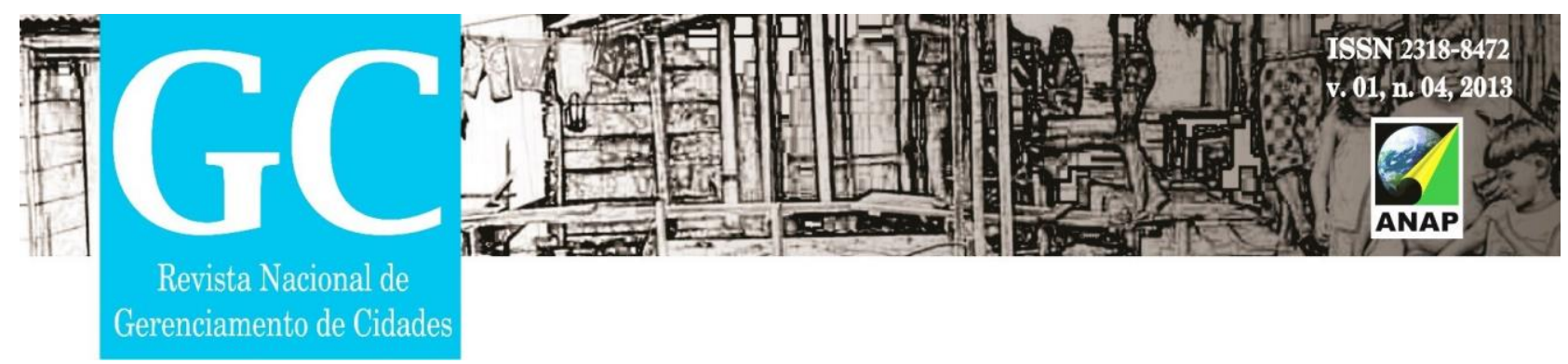

apartamentos, fugindo das soluções valorizadas pelo mercado. Oferecem plantas de unidades mais variadas e com áreas úteis maiores, proporcionando qualidade de vida, independentemente da falta de áreas para lazer luxuosas.

Apresentaram desenho urbano em respeito ao meio ambiente, com quadras abertas e parceladas em condomínios, variações tipológicas, construções adaptadas aos desníveis topográficos para evitar as movimentações de terra, unidades comerciais, área de lazer, unidades adaptáveis, área verde, flexibilidade e sistemas de drenagem nas vielas.

E observarmos também a preocupação em atender a todas as necessidades, tanto dos moradores, quanto as relacionadas à adaptação de custos, de materiais utilizados, a estética da construção e a questão de sustentabilidade. É importante resaltar, que o conjunto habitacional desenvolvido por eles, fugiu das fachadas "padronizadas" e desenvolveram ótimas opções com qualidade arquitetônica.

Os problemas de alagamentos foram resolvidos com as soluções de drenagem das águas pluviais (áreas permeáveis), mas devido à declividade das ruas não eliminada nos projetos, talvez em chuvas com maior intensidade os sistemas desenvolvidos não sejam suficientes.

Com o resultado de toda essa análise, percebemos que é possível construir cidades e resolver os problemas de déficit de habitação no país, sem prejudicar o meio ambiente e proporcionando qualidade de vida à toda população, independentemente da classe social. Devemos oferecer igualdade social e condições de vida digna a todos. Não pensando somente no presente momento em que vivemos, mas nas futuras gerações que estão por vir.

\section{CONSIDERAÇÕES FINAIS}

Conclui-se, portanto, que para uma urbanização mais sustentável é necessário uma política de conservação nacional sobre o futuro das nossas cidades, e para isso, é preciso: disponibilizar o acesso a terra urbanizada para a classe de baixa renda; minimizar os entraves político-administrativos; melhorar os lucros da construção; exigir fiscalização dos órgãos competentes; não generalizar apenas um "ideal" de cidade; 


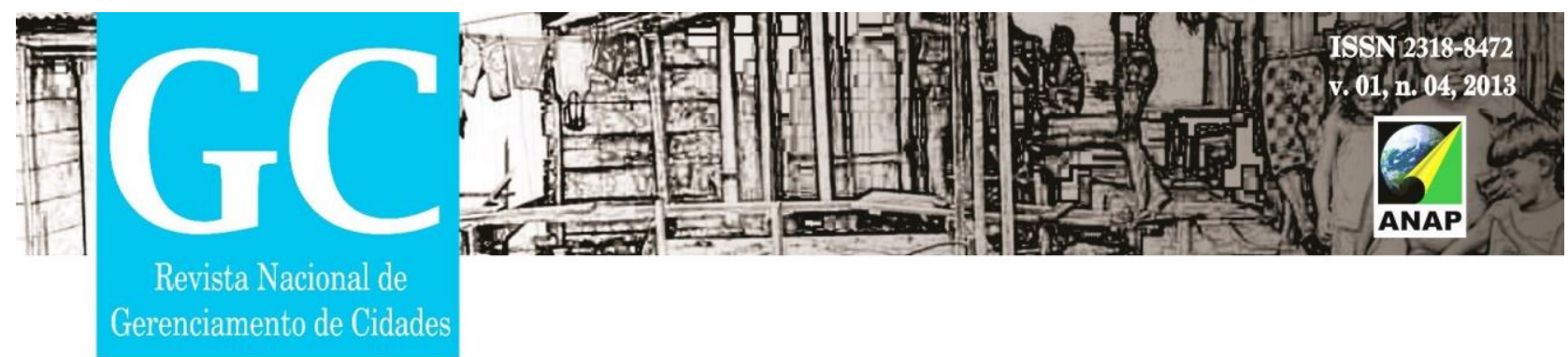

promover o transporte público; e criar um novo uso aos milhares de imóveis abandonados nos grandes centros urbanos.

O setor industrial é quem deve alcançar as condições em obras com amortização dos investimentos e formação de mão de obra qualificada, além de melhores condições de trabalho, proporcionando volume, qualidade, economia, diversidade e velocidade de produção, garantindo sistemas de pré-fabricação com diversidade construtiva, redução dos insumos e dos impactos ambientais.

É necessária a reconquista da "cidade" como espaço das relações sociais, de vida e de convívio em conjunto com projetos arquitetônicos e urbanos que eliminará o caos urbano que o Brasil vive hoje, assegurando cidades mais dignas e justas para as próximas gerações.

\section{REFERÊNCIAS}

O QUE É PLANEJAMENTO URBANO. Disponível em: <http://santacruz.rs.gov.br/geo/geo/plan.htm>. Acesso em: 20 set. 2013.

FERREIRA, João Sette Whitaker. Produzir casas ou construir cidades? Desafios para um novo Brasil urbano. 1. ed. São Paulo: LABHAB ; FUPAM, 2012. 